\title{
Powder for Concentrate for Solution for Injection/Infusion Dosage Form
}

National Cancer Institute

\section{Source}

National Cancer Institute. Powder for Concentrate for Solution for Injection/Infusion

Dosage Form. NCI Thesaurus. Code C149814.

Solid sterile preparation consisting of one or more powders intended to be dissolved in the specified liquid to obtain a concentrate for solution for injection/infusion, which must subsequently be diluted before administration as a solution for injection/infusion. 